\title{
Medical nutrition therapy and clinical outcomes in critically ill adults: A European multinational, prospective observational cohort study (EuroPN)
}

\section{Martin Matejovic}

Charles University and University Hospital in Pilsen

Olivier Huet

CHRU la Cavale Blanche

Karolien Dams

University of Antwerp

Gunnar Elke

University Medical Center Schleswig-Holstein

Clara Alonso Vaquerizo

Fuenlabrada University Hospital (Hospital Universitario de Fuenlabrada)

Akos Csomos

MH EK Honvedkorhaz, Budapest

Łukasz J Krzych

Medical University of Silesia

Romano Tetamo

Ospedale AUSL Reggio Emilia

Zudin Puthucheary

Queen Mary University of London

Olav Rooyackers

Karolinska Institute

Inga Tjäder

Karolinska University Hospital

Helmut Kuechenhoff

Ludwig-Maximilians-Universität München

Wolfgang $\mathrm{H}$. Hartl

Klinikum der Universitaet, Ludwig-Maximilians-Universität Muenchen

Michael Hiesmayr ( $\nabla$ michael.hiesmayr@meduniwien.ac.at )

Medical University Vienna 
Keywords: Critical illness, mechanical ventilation, weaning, survival, nutrition, calorie, protein

Posted Date: February 10th, 2022

DOI: https://doi.org/10.21203/rs.3.rs-1338063/v1

License: (c) (1) This work is licensed under a Creative Commons Attribution 4.0 International License. Read Full License 


\section{Abstract}

Background: Medical nutrition therapy may be associated with clinical outcomes in critical ill patients with prolonged ICU stay. We wanted to assess nutrition practices in European intensive care units (ICU) and their relevance for clinical outcomes.

Methods: Prospective multinational observational study including patients in ICU $\geq 5$ days with a followup until day 90. Macronutrient intake during the first 15 days after ICU admission was compared with targets recommended by ESPEN guidelines. We determined independent predictors of macronutrient intake and modelled associations between three categories of daily calorie and protein intake (low: $<10$ $\mathrm{kcal} / \mathrm{kg},<0.8 \mathrm{~g} / \mathrm{kg}$; moderate: $10-20 \mathrm{kcal} / \mathrm{kg}, 0.8-1.2 \mathrm{~g} / \mathrm{kg}$, high: $>20 \mathrm{kcal} / \mathrm{kg} ;>1.2 \mathrm{~g} / \mathrm{kg}$ ) and the timevarying hazard rates of 90 -day mortality or successful weaning from invasive mechanical ventilation (IMV). Hazard ratios were calculated from piece-wise exponential additive mixed models to compare several different hypothetical medical nutrition therapies.

Results: 1172 patients with median [Q1;Q3] APACHE II score of 18.5 [13.0;26.0] were included, and 23.5\% died until day 90. Median length of ICU stay was 10.0 [7.0;16.0] days, $73.9 \%$ of patients could be weaned from invasive mechanical ventilation. Patients reached on average $83.1 \%[59.2 ; 106.6]$ and $64.5 \%$ [41.4;90.9] of ESPEN calorie and protein recommended targets, respectively. Whereas specific reasons for ICU admission (especially respiratory diseases requiring IMV) were associated with higher intakes, a lack of nutrition on the preceding day was associated with lower intakes. Daily moderate calorie and moderate protein intake were associated with higher probability of successful weaning, and, for calories, lower hazards of death compared to a lower intake. There was no evidence that a high calorie or protein intake was associated with further outcome improvements.

Conclusions: Calorie intake was mainly provided according to the recommended targets by the ESPEN guideline, but protein intake was lower. Early moderate daily calorie and protein intakes were associated with improved clinical outcomes.

Trial Registration: ClinicalTrials.gov NCT04143503, registered on October 25, 2019

\section{Background}

Medical nutrition therapy is an integral part of critical care. The current European Society for Clinical Nutrition and Metabolism (ESPEN) critical care guidelines recommend a progressive ramp-up of medical nutrition therapy providing $<70 \%$ of measured energy expenditure or of estimated needs during the early phase of acute illness, and up to $80-100 \%$ after day three, to limit the risk of overfeeding and refeeding syndrome (1). In parallel, $1.3 \mathrm{~g} / \mathrm{kg}$ protein equivalents per day can be delivered progressively. These recommendations are more conservative than those propagated by the preceding ESPEN guideline (2) acknowledging evidence of a detrimental effect of high calorie intakes during the acute phase, and that a higher protein intake during the first week of critical illness may improve clinical outcomes (3). 
The majority of critically ill patients do not receive adequate nutritional intake according to guideline targets $(4,5)$. Currently, there is no study assessing the level of adherence to the new ESPEN recommendations. The evidence from RCTs and observational studies on the specific amounts of calories and protein and the timing of medical nutrition therapy and its relation to clinical outcomes, e.g., weaning from invasive mechanical ventilation (IMV) and survival (6-14), is inconsistent, and few studies have focused on long-stay ICU patients. Consequently, there is also a strong need to re-assess the importance of macronutrient intake for clinical outcomes.

The objective of the present study was to describe medical nutrition therapy for up to 15 days after ICU admission for critically ill patients with a minimum length of stay (LOS) of 5 days in European ICUs. Additionally, associations between calorie and protein intake with time to weaning from invasive mechanical ventilation and 90-day survival time were assessed using a novel combination of established statistical techniques which considered time-dependency of medical nutrition therapy effects and interferences of confounding by indication.

\section{Methods}

\section{Study design}

The present study was a multinational, prospective observational cohort study conducted between November 2019 and July 2020 in 11 European countries (Austria, Belgium, Czech Republic, France, Germany, Hungary, Italy, Poland, Spain, Sweden, and United Kingdom), approved by the respective Ethics Committees and Institutional Review Boards. The study protocol was published previously (15).

\section{Patients}

The study included critically ill adults, aged 18-95 years, with a body mass index (BMI) of $\geq 18.5 \mathrm{~kg} / \mathrm{m}^{2}$ and $\leq 45 \mathrm{~kg} / \mathrm{m}^{2}$, hospitalized in any type of ICUs for at least five consecutive days, and receiving medical nutrition therapy as part of ICU care. Exclusion criteria included: burns; chronic, pre-existing neuromuscular, psychiatric, or neurological conditions precluding assessment of functional status; home nutritional support or chronic mechanical ventilation before or at the time of ICU admission; palliative care; or concurrent enrolment in any nutrition-related interventional study. After informed consent, demographic, clinical characteristics, and nutrition variables were recorded for eligible patients until ICU discharge, death, or maximum day 15 of ICU stay. We assessed 90-day survival time, and patient's mobility status (ICU Mobility Score (16), IMS) at baseline, reflecting IMS values before ICU admission, and at day 15, 30, and 90 after ICU admission. Patients were followed up until day 90 after ICU admission, either via telephone, or visited by site personnel.

\section{Outcomes}

The primary outcome of this study was described as the median [Q1;Q3] calorie and protein balances, calculated as the percentage deviation from the ESPEN targets during the first 15 days of ICU stay. 
Intakes were calculated from all nutritional sources, i.e., oral nutrition, oral nutritional supplements (ONS), enteral nutrition (EN), parenteral nutrition (PN), and non-nutritional calories, i.e., propofol, clevidipine, citrate, or glucose. Since ESPEN guidelines do not define explicitly the daily targets for the acute phase, we approximated daily targets based on an estimated energy expenditure of $25 \mathrm{kcal} / \mathrm{kg}$ per day: 10 $\mathrm{kcal} / \mathrm{kg}$ body weight (BW) on day 1 ( $\approx 40 \%$ of energy expenditure), $15 \mathrm{kcal} / \mathrm{kg}$ on day 2 and $3(\approx 60 \%$ of energy expenditure), $20 \mathrm{kcal} / \mathrm{kg}$ on day 4 to 6 ( $\approx 80 \%$ of energy expenditure), $25 \mathrm{kcal} / \mathrm{kg}$ on day 7 to 15 $(\approx 100 \%$ of energy expenditure).

Daily protein targets were set at $0.6 \mathrm{~g} / \mathrm{kg}$ on day $1,0.9 \mathrm{~g} / \mathrm{kg}$ on day 2 and 3 , and $1.3 \mathrm{~g} / \mathrm{kg}$ on days 4 to 15 . Calculations were based on actual (admission) BW for patients with a BMI $<30 \mathrm{~kg} / \mathrm{m}^{2}$ and on adjusted BW, determined by the formula: (actual BW - ideal BW) $\times 0.33+$ ideal BW when BMI was $\geq 30 \mathrm{~kg} / \mathrm{m}^{2}$, estimating ideal BW as per Peterson (17).

Other outcomes were time-to-weaning from IMV, defined as the time in days from the start of IMV to either successful weaning (irrespective of subsequent death) or to death while intubated, 90-day survival time.

\section{Quantifying macronutrient intake}

Daily protein and calorie intake was collected from the day of ICU admission (day \#1 in ICU) for a maximum of 15 days. Documentation of calorie and protein intake was stopped after a patient had been discharged from the ICU, or after day 15 for patients longer in the ICU. Total daily protein intake was classified by using established thresholds (18) defining three different levels based on the daily amount

of received protein (level I, low: $<0.8 \mathrm{~g}$ protein $/ \mathrm{kg}$; level II, moderate: 0.8-1.2 g protein $/ \mathrm{kg}$; level III, high: $>1.2$ g protein $/ \mathrm{kg}$ ).

Classification of total daily calorie intake was based on the assumption of a maximum energy expenditure of $30 \mathrm{kcal} / \mathrm{kg}$ per day during the acute phase (19), and on established categories of expenditure of $<33.3 \%, 33.3-66.6 \%,>66.6 \%(20,21)$, resulting in the categories per $\mathrm{kcal} / \mathrm{kg}$ : level l, low: $<$ $10 \mathrm{kcal} / \mathrm{kg}$ per day; level II, moderate: $10-20 \mathrm{kcal} / \mathrm{kg}$ per day; level III, high: $>20 \mathrm{kcal} / \mathrm{kg}$ per day.

\section{Statistical analyses}

For descriptive statistics, continuous variables were described as number of patients with valid/missing observations, and non-normally distributed data was described as median and interquartile range [Q1;Q3] values.

Independent predictors for daily calorie and protein intakes were identified using linear mixed-effect models with repeated measures and reported as estimates and $95 \% \mathrm{Cl}$. Study site was included as random effect, and ICU day as fixed effect. Discharge date was excluded since mostly partial nutrition data was available depending on discharge time. Continuous variables were modelled by flexible penalized spline to account for possible nonlinear relationships with the outcome variables. A p-value $<0.05$ was considered a significant association. 
To estimate hazard rates of medical nutrition therapy for time until successful weaning and time until death (while still being intubated) in a subgroup of patients with IMV between day 1 to 3 , we used piecewise exponential additive mixed models $(22,23)$, which allowed for an easy accommodation of timevarying covariates such as nutrition, and had been recently extended to cumulative effects $(22,24)$ and to competing risks (25). R packages pammtools (24) and mgcv (26) were used to estimate corresponding models. This novel combination of statistical techniques has already been used before to estimate complex associations between nutrient intakes and different outcomes $(27,28)$.

A similar approach was used for modelling associations of medical nutrition therapy with survival time. Confounders included demographic and clinical patient characteristics, and study site as random effect (additional file, eTables 1-4). We also used leads and lags. The lead time thereby defines the putative delay until an effect of nutrition. The lag time aims to minimize the indication bias originating from possible changes of calorie intake prior to weaning from IMV, discharge, or death $(23,27)$.

To facilitate interpretation of the time-varying hazard ratios (HR) between nutrition and outcome, we predefined different hypothetical time-varying medical nutrition therapies with three levels of calorie or protein intake (low, moderate, high) in combination with an early (day 1 to 4) and late (after day 4) period over days 1-15 (Table 1). Importantly, these hypothetical medical nutrition therapies represent concepts similar to clinically established nutrition protocols, but do not reflect selected patient cohorts contained in this study. We modelled associations between these hypothetical medical nutrition therapies and outcomes by designing six pairwise medical nutrition therapy comparisons while controlling for confounders. All hazard ratios of these pairwise comparisons of different hypothetical medical nutrition therapies were calculated under the assumption that all other variables were fixed.

For survival analysis, our statistical model required information on calorie and protein intake for all 15 days after ICU admission, even if a patient had been discharged from the ICU before. Recent surveys showed that after ICU discharge patients on average only receive $0.8-1.0 \mathrm{~g}$ protein $/ \mathrm{kg}$ per day and 14-18 $\mathrm{kcal} / \mathrm{kg}$ per day (29). On the days before ICU discharge, our surviving patients had on average an intake of $1.2 \mathrm{~g}$ protein $/ \mathrm{kg}$ per day and of $20 \mathrm{kcal} / \mathrm{kg}$ per day. Therefore, to account for missing days with medical nutrition therapy on an individual basis, we imputed a daily calorie and protein intake reflecting $80 \%$ of the patient's average preceding intake of the three last days prior to discharge; no other imputations were performed.

A detailed explanation of the methodology, and how to translate these pairwise comparisons into the coxtype models is provided in the additional file (eAnnex 1 , and eFigure 1 ).

\section{Results}

\section{Study population}

A total of 3086 patients were screened in 77 ICUs from 11 countries. 1213 patients were enrolled (additional file, eFigure 2, eTable 5), of whom 34 were excluded, and 7 dropped out, while 1172 underwent 
analysis. Patient characteristics are shown in Table 2. By day 15, 344 (29.4\%) patients were still in ICU, $474(40.4 \%)$ still hospitalized, and $352(30.0 \%)$ had been discharged home or transferred to another healthcare facility, with 2 patients $(0.2 \%)$ lost to follow up. By day $90,71(6.1 \%)$ were still in hospital or ICU. Regarding mortality, 95 (8.1\%) and 275 (23.5\%) patients had died by day 15 and day 90 , respectively (Kaplan-Meier Plot in eFigure 3).

Half of the 813 patients requiring IMV between day 1 to 3 after ICU admission were weaned by day 8 . A total of 601 (73.9\%) weaning events occurred during the 15-day observation period (Cumulative incidence plot in eFigure 4).

\section{Calorie and protein intake}

Nutrition started on median ICU day $2.0[2.0 ; 4.0]$ for PN, $2.0[2.0 ; 4.0]$ for EN and 3.0 [2.0;6.0] for oral nutrition/ONS. The provision of calories and proteins increased progressively over the first 5 days (Figure 1 ; eFigures 5 and 6 in additional file show daily median intakes excluding patients without any nutrition). On day 3 of ICU admission, combined enteral /oral calorie intake was on average $8 \mathrm{kcal} / \mathrm{kg}$ per day, and increased to about $13 \mathrm{kcal} / \mathrm{kg}$ per day between days 6 and 14. Average parenteral calorie intake was 5 $\mathrm{kcal} / \mathrm{kg}$ per day on day 3, and increased to about $7 \mathrm{kcal} / \mathrm{kg}$ per day between days 6 and 14 .

Median daily calorie and protein intake was 15.9 [10.8;2.2] kcal $/ \mathrm{kg}$ and $0.7[0.4 ; 1.0] \mathrm{g} / \mathrm{kg}$, respectively. Patients met on average $83 \%[59.2 ; 106.6]$ of the calorie and $65 \%[41.4 ; 90.9]$ of the ESPEN protein targets over the study period.

Median daily calorie intake was $2.3[0.0 ; 6.5] \mathrm{kcal} / \mathrm{kg}$ in the low category ( $<10 \mathrm{kcal} / \mathrm{kg}$ day), 15.5 $[12.8 ; 18.0] \mathrm{kcal} / \mathrm{kg}$ in the moderate category $(10-20 \mathrm{kcal} / \mathrm{kg}$ day), and $26.3[23.1 ; 30.3] \mathrm{kcal} / \mathrm{kg}$ in the high category (>20 kcal $/ \mathrm{kg}$ day). Median daily protein intake was $0.28[0.0 ; 0.55] \mathrm{g} / \mathrm{kg}$ in the low category $(<0.8$ $\mathrm{g} / \mathrm{kg}$ day), $1.0[0.90 ; 1.11] \mathrm{g} / \mathrm{kg}$ in the moderate category $(0.8-1.2 \mathrm{~g} / \mathrm{kg}$ day), and $1.51[1.36 ; 1.76] \mathrm{g} / \mathrm{kg}$ in the high category $(>1.2 \mathrm{~g} / \mathrm{kg}$ day). The amount of information present in each of these categories (i.e., low, moderate, high) was well balanced (additional file, eTable 6).

Lack of nutrition on the preceding day $(\mathrm{p}<0.001)$ and regular assessment of individual nutritional needs $(p<0.001)$, performed in $73(94.8 \%)$ of the 77 participating ICUs, was associated with a lower calorie and protein intake, while the need for IMV on the preceding day $(\mathrm{p}<0.001)$ and a respiratory or hepatic reason for ICU admission ( $p<0.001)$ was associated with a higher calorie and protein intake (additional file, eTables 7 and 8).

\section{Nutrition and outcome}

The associations of the variables in the confounder model with the outcome are presented in the additional file, eTables 1 to 4 . Percentage of total calories given via the enteral and/or oral route between day 1 and day 5 after admission was not significantly associated with survival time and time until successful weaning. 
To analyze associations with outcome, we compared a time-varying moderate intake (feeding of 10-20 $\mathrm{kcal} / \mathrm{kg}$ or $0.8-1.2 \mathrm{~g}$ protein $/ \mathrm{kg}$ ) with a constant low intake (feeding of $<10 \mathrm{kcal} / \mathrm{kg}$ or $<0.8 \mathrm{~g}$ protein $/ \mathrm{kg}$ ) (Figure 2 and 3, columns 1-3). Irrespective from timing, providing daily $10-20 \mathrm{kcal} / \mathrm{kg}$ was associated with a longer survival time and shorter time on IMV compared to less calories. This significant association was particularly evident when the difference in calorie supply was present after day 5 . Associations for protein intake were weaker, with only moderate protein intake from day 1 to day 15 significantly associated with earlier weaning from IMV, but not with survival.

Comparison of a time-varying high intake (feeding of $>20 \mathrm{kcal} / \mathrm{kg}$ or $>1.2 \mathrm{~g}$ protein $/ \mathrm{kg}$ ) with a constant moderate intake (Figure 2 and 3, columns 4-6) revealed that, irrespective from timing, high calorie and protein intakes were both associated with a longer time until extubation $(H R<1$ in panels in rows 2 and 3 , column 5), but not with a shorter survival time.

Most patients were independently mobile before ICU admission (Table 1), while IMS values were lower on days 15 and 30, yet, returned to baseline by day 90. At all timepoints, patients still in hospital had a lower IMS value than discharged patients (additional file, eFigure 7). Confounder-adjusted associations between nutrition and IMS values were not analyzed because of limitations (23) from both a substantial ceiling and floor effect (additional file, eTable 9).

\section{Discussion}

To our knowledge, this is one of the largest prospective studies providing real-world evidence about nutrition and its associations with clinical outcomes in a mixed population of critically ill adult patients treated in European ICUs during a minimum ICU LOS of 5 days. Median calorie and protein intake during the first 15 days after ICU admission was 15.9 [10.8;21.2] kcal/kg and $0.7[0.4 ; 1.0] \mathrm{g} / \mathrm{kg}$ per day, respectively. Interestingly, these intakes are very similar to observations $(14.3 \mathrm{kcal} / \mathrm{kg}$ day, $0.7 \mathrm{~g}$ protein/kg day) made about ten years ago in a comparable cohort of international and European critically ill patients which had been included into the International Nutrition Survey $(4,30)$. Similar to this longitudinal survey, we also identified a ramp-up of intakes reaching a plateau after about one week after ICU admission.

Although our patients met on average $83 \%$ of the recent calorie ESPEN targets, an apparently stable clinical practice throughout a decade suggests that this comparatively high compliance with recommendations is not a response to conservative ESPEN guidelines but rather represents a continuation of established clinical practice. The same explanation is likely for the poor adequacy of protein intake which was about one third lower than recent protein ESPEN targets but had also remained stable over time $(4,30)$.

Remarkably, the current clinical practice is already following the recently published recommendations by a group of experts in critical care nutrition aiming to provide practical tips in complement to the ESPEN guidelines (31). During the early phase energy intakes should be lower than energy expenditure and should be increased to match energy expenditure later. The authors also recommended a low protein 
intake (max $0.8 \mathrm{~g} / \mathrm{kg}$ per day) during the early phase of critical illness, while a protein target of $>1.2$ $\mathrm{g} / \mathrm{kg} /$ day could be considered during the rehabilitation phase (31).

It should be noted that our average calorie intake was lower than that found by the recent, large European nutritionDay ICU initiative (about $21 \mathrm{kcal} / \mathrm{kg}$ day) (32) and Latin American Screening Day (about 24 $\mathrm{kcal} / \mathrm{kg}$ day) (5). This discrepancy may be explained by a different study design. In contrast to our longitudinal study, both initiatives used a point-prevalence design favoring the inclusion of critically ill patients treated on the ICU beyond day 15 after ICU admission.

Analysis of independent determinants of macronutrient intake in our cohort revealed that specific comorbidities (especially respiratory diseases requiring invasive ventilation) predicted a higher intake, whereas intake was lower if there had been a regular assessment of nutritional needs. This observation appears to contradict results of the International Nutrition Survey where the presence of a feeding protocol at the site level was associated with higher intakes (4). Feeding protocols communicated at the time of the International Nutrition Survey clearly aimed at the provision of more enteral calories in the light of a high target ( $24 \mathrm{kcal} / \mathrm{kg}$ day in the acute phase). Current assessment of individual nutritional needs, however, may have more likely considered the phase of the disease favoring lower intakes during the acute phase.

A major finding of our study was that intensivists had provided moderate amounts that were associated with the best outcomes. Optimal, phase-dependent targets for calorie and protein intake have been subject to an intense discussion throughout more than two decades. A specific limiting effect was the extremely varying design, patient selection and analytical approaches of clinical studies giving room to different interpretations (33). Limitations of observational studies result from an inadequate ratio between the number of events and confounding variables, and from the ignorance of confounding by indication, competing risks, time-dependency of macronutrient intake, and time-variation/non-linearity of associations, causing a considerable bias $(34,35)$.

Only recently, several randomized studies provided a clearer picture of an optimal medical nutrition therapy especially in terms of calorie intake. Meta-analyses on this subject have been reviewed (36), suggesting that calorie intake either is unimportant for outcomes, or that there might be a U-shaped relationship between calorie intake and mortality or morbidity (minimum with a moderate calorie intake), which is in line with our findings. Our data therefore support the harms associated with underfeeding and overfeeding, yet a universally accepted mechanism of action has not been established.

Quality of evidence for recommendations on protein intake is still low because of a lack of specific randomized studies. To overcome this knowledge gap, some authors extracted protein intake from large, randomized studies originally designed to study the effects of a different calorie intake. Two recent metaanalyses found that protein intakes between 0.7 and $1.3 \mathrm{~g} / \mathrm{kg}$ day were unimportant for morbidity or mortality $(3,37)$ and a post hoc analysis of the PermiT trial $(38)$ revealed similar results. Our results suggest a U-shaped relationship between protein and time until weaning, but not mortality. Compared to lower or higher intakes, an intake between 0.8 and $1.2 \mathrm{~g} / \mathrm{kg}$ per day was associated with a shorter time 
until extubation, particularly if provided throughout the whole observation period. These findings suggests that nutrition strategies enabling a moderate calorie supply of $10-20 \mathrm{kcal} / \mathrm{kg}$ per day and moderate protein intake up to $\sim 1.2 \mathrm{~g} / \mathrm{kg}$ per day early after ICU admission have the potential to improve patient care.

The impact of nutrition on the functional recovery of critically ill patients remains unclear. Prior studies have shown inconsistent effects, presumably due to variabilities in the assessment of muscle function, different follow-up times, large drop-out rates, and, in some cases, difficulties to obtain data post ICU/hospital discharge $(12,35,39-41)$. In our study, the associations of macronutrient intakes with IMS values could not be assessed because of a ceiling effect, not allowing to identify differences in IMS values in patients able to walk independently.

\section{Strengths and limitations}

The main strength of this study is the prospective design guaranteeing a high data quality, the large number of patients. Our study reflects the current clinical practice of medical nutrition therapy in a diverse medical/surgical population of moderately severe, long-staying critically ill patients in European ICUs. Furthermore, for all patients, survival was followed up over 90 days after ICU admission.

This study is mainly limited by its observational nature, only allowing to assess associations between macronutrient intake and clinical outcomes, which may still be affected by potential unmeasured confounders despite the robust methodology used with respect to confounding by indication. We thereby minimized interferences from a better nutritional tolerance prior to discharge/extubation and from a worse tolerance prior to death. By adjusting to oral/enteral calorie intake (in \% of total intake) during the first five days of ICU stay, we directly accounted for interferences from gastrointestinal function immediately after the insult, being presumably better with oral/enteral, and worse with parenteral feeding.

Our results suggest that these strategies were effective: If confounding by indication had been strong, we would have observed significant associations between an increasing intake during the acute phase and a progressively better outcome, which was not the case.

Selection bias might have resulted from the nutrition-oriented nature of the study, encouraging a higher participation of sites interested in nutrition. Finally, a bias might arise from including patients in your analysis up to a BMI of $45 \mathrm{~kg} / \mathrm{m}^{2}$. According to recent results, however, associations between hypothetical diets and outcomes in patients with a BMl $>30 \mathrm{~kg} / \mathrm{m}^{2}$ are qualitatively comparable to those with a lower BMI (28).

\section{Conclusion}

This prospective multinational cohort study in critically ill patients staying more than 5 days in the ICU showed that median calorie intake was slightly below the recommend target of $20-25 \mathrm{kcal} / \mathrm{kg}$ of the 2019 ESPEN guideline, whereas protein intake was clearly below the 2019 recommendation of $1.3 \mathrm{~g} / \mathrm{kg}$. 
Outcome analyses showed that moderate daily macronutrient intake of $10-20 \mathrm{kcal} / \mathrm{kg}$ and $0.8-1.2 \mathrm{~g}$ protein/kg, both approaching currently recommended targets (31), were associated with earlier weaning from IMV, and, for calories, with longer survival compared to a daily intake above or below these moderate intakes.

\section{Abbreviations}

APACHE Acute Physiology and Chronic Health Evaluation score, second version II

\begin{tabular}{ll} 
BMI & Body Mass Index \\
\hline BW & Body Weight \\
\hline EN & Enteral Nutrition \\
\hline
\end{tabular}

ESPEN European Society for Clinical Nutrition and Metabolism (previously known as European Society of Parenteral and Enteral Nutrition)

\begin{tabular}{ll}
\hline HR & Hazard Ratio \\
\hline ICU & Intensive Care Unit \\
\hline IMS & ICU Mobility Score \\
\hline IMV & Invasive Mechanical Ventilatio \\
\hline LOS & Length Of Stay \\
\hline ON & Oral Nutrition \\
\hline ONS & Oral Nutrition Supplements \\
\hline PN & Parenteral Nutrition \\
\hline RCT & Randomized, Controlled Trial
\end{tabular}

\section{Declarations}

Ethical approval and consent to participate: This non-interventional study was reviewed and approved by the ethics committee of the Medical University Vienna, Vienna, Austria (approval number 1678/2019), and the respective ethical committees from participating sites at country and/or local level, as required by regulations. Written informed consent was obtained from all participating patients and/or legally appointed representatives, whenever applicable, after approval from their respective ethics committee. All applicable data protection regulations were followed to ensure patient confidentiality.

Consent for publication: Not applicable

Availability of data and materials: The datasets generated and analyzed during the current study are property of the study sponsor and can be requested for reasonable research purposes. 
Competing Interests: M. Hiesmayr has received lecture fees and travel support from Fresenius Kabi, Nestlé, Baxter, SSPC, consulting fees from Fresenius Kabi, and unrestricted research grants from Baxter and Fresenius Kabi to Medical University Vienna. M. Matejovic has received lecture fees from Fresenius Kabi, Baxter, Nutricia and consulting fees and travel support from Fresenius Kabi. C. Vaquerizo has received lecture fees and travel support from Fresenius Kabi, Nestlé Healthcare Nutrition, Abbott Nutrition and Vegenat Nutrisens, and consulting fees from Fresenius Kabi and Vegenat Nutrisens. G. Elke has received lecture fees and travel support from Fresenius Kabi, Baxter and consulting fees and travel support from Cardinal Health, Fresenius Kabi and Nutricia. K. Dams has received lecture fees from Fresenius Kabi, Baxter, Nestlé and consulting fees and travel support from Fresenius Kabi. R. Tetamo has received lecture fees and travel support from Fresenius Kabi. W. Hartl has received travel support from Fresenius Kabi. H. Kuechenhoff has received travel support and consulting fees from Fresenius Kabi. 0. Rooyackers has received lecture and consulting fees from Fresenius-Kabi, Nutricia, Nestle and Baxter. The rest of the authors have no conflicts of interest to declare in relation with this study.

Funding: This study was sponsored by Fresenius Kabi Deutschland, GmbH, Else-Kroener-Strasse 1, D61352 Bad Homburg v. d. H., Germany.

Author contributions: All authors provided equal input for the concept and design of this study and coordinated the acquisition of data in their hospitals and respective countries. W. Hartl and $\mathrm{H}$. Kuechenhoff provided advise during the elaboration of the statistical analysis plan, and for the methods section of this manuscript. W. Hartl and M. Hiesmayr wrote the main manuscript text. A. Csomos, $\mathrm{K}$. Dams, G. Elke, O. Huet, L. Krzych, M. Matejovic, Z. Puthucheary, O. Rooyackers, R. Tetamo, I. Tjader, C. Vaquerizo had an equal contribution to the elaboration of this manuscript. All authors read and approved the final manuscript, being fully accountable for ensuring its integrity and accuracy.

Acknowledgments: The authors thank all coordinating investigators in the participant countries: Austria: Dr. Bernard Zapletal; Belgium: Dr. Marc Simon, Dr. Nicolas Serck, Dr. Eric Gilbert, Prof. Dr. Jean-Charles Preiser, Dr. Denis Glorieux, Dr. Patrick Druwe, Dr. Xavier Wittebole, Prof. Dr. Elisabeth De Waele; Czech Republic: Dr. Pavel Dostal, Dr. Jan Maňák, Dr. Olga Klementová, Assoc Prof. Jan Benes, Dr. Michal Lips, Assoc Prof. Tomas Vymazal, Dr. Eduard Havel, Dr. Igor Sas, Dr. Michal Šenkyř́k, Dr. Jiri Matyas, Dr. Marek Fencl; France: Dr. Laurent Carteron, Dr. Michel Durand, Dr. Desire Samba, Dr. Julien Birckener, Dr. Jerome Morel, Dr. Antoine Sannini, Dr. Pierre Saint-Léger, Dr. Sébastien Perbet, Dr. Julien Crozon, Dr. Charles Cerf, Dr. Martine Ferrandiere, Prof. Sigismond Lasocki; Germany: Dr. Simon Weigand, Prof. Dr. med. Arved Weimann, Dr. med. Stefan Angermair, Prof. Dr. med. Christian Wunder, Dr. med. Norbert Reckefuß, Prof. Dr. Jörg Engel, Dr. med. Jan Matthias Kruse, Prof. Dr. med. Ahmed Madisch; Hungary: Dr. Béla Gál, Dr. Ágnes Sárkány, Dr Klicsu László, Dr. Ilona Bobek, Prof. Dr. Béla Fülesdi; Italy: Prof. Assoc. Davide Alberto Chuimello, Prof. Gilda Cinnella, Dr. Mario lannotti, Dr. Fernando Chiumento, Dr. Elia Graziani, Dr. Giovanni Giuliani; Poland: Dr. Karina Barbara Stefańska-Wronka, Dr n. med. Robert Włodarski, Dr Irmina KapturKomorowska, Dr n. med. Maciej Gawor, Dr. Karolina Haas, Dr Magdalena Weglowska-Jedryka; Spain: Dr. Juan Carlos López Delgado, Dr. Ana Martín Luengo, Dr. Mar Juan, Dr. Luis Servia, Dr. Eva María Menor Fernández, Dr. Amalia Martínez de la Gándara, Dr. Carol Lorencio, Dr. Mireia Ferreruela, Dr. María Gero; 
Sweden: Dr. Inga Tjäder; United Kingdom: Dr. Nigel Scawn, Prof. Dr. Med. Ingeborg Welters. The authors also thank Philipp Kopper, M.Sc., from the Ludwig Maximilian University of Munich, for statistical support, and the following employees of Fresenius Kabi for their support during the conduct of this study: Jean-Francois Baron, MD; Margot Crucet Peregrino PhD; Valentin Faerber, PhD; Eva Fries-Schaffner, PhD; Martín Hernández González, MD; Thomas Lescot, MD; Xieran Li, M. Sc.; Petra Loedige, MD; Anna Mallol, PhD; Claudia Miranda-Foca-Fuchs, M. Sc.; Astrid Spindler, PhD; John Stover, MD; Melanie Streicher, PhD; Anne-Sophie Tepenier, M. Sc.; Martin Westphal, MD, MBA

\section{References}

1. Singer P, Blaser AR, Berger MM, Alhazzani W, Calder PC, Casaer MP, et al. ESPEN guideline on clinical nutrition in the intensive care unit. Clinical nutrition. 2019;38(1):48-79.

2. Singer P, Berger M. van den BG, Biolo G, Calder P, Forbes A, Griffiths R, Kreyman G, Leverve X, Pichard C (2009) ESPEN guidelines on parenteral nutrition: intensive care. Clin Nutr.28:387-400.

3. Lee Z-Y, Yap CSL, Hasan MS, Engkasan JP, Barakatun-Nisak MY, Day AG, et al. The effect of higher versus lower protein delivery in critically ill patients: a systematic review and meta-analysis of randomized controlled trials. Critical Care. 2021;25(1):1-15.

4. Heyland DK, Dhaliwal R, Wang M, Day AG. The prevalence of iatrogenic underfeeding in the nutritionally 'at-risk'critically ill patient: Results of an international, multicenter, prospective study. Clinical Nutrition. 2015;34(4):659-66.

5. Vallejo KP, Martínez CM, Adames AAM, Fuchs-Tarlovsky V, Nogales GCC, Paz RER, et al. Current clinical nutrition practices in critically ill patients in Latin America: a multinational observational study. Critical care. 2017;21(1):1-11.

6. Arabi YM, Aldawood AS, Haddad SH, Al-Dorzi HM, Tamim HM, Jones G, et al. Permissive underfeeding or standard enteral feeding in critically ill adults. New England Journal of Medicine. 2015;372(25):2398-408.

7. Zusman O, Theilla M, Cohen J, Kagan I, Bendavid I, Singer P. Resting energy expenditure, calorie and protein consumption in critically ill patients: a retrospective cohort study. Critical care. 2016;20(1):18.

8. Bendavid I, Zusman O, Kagan I, Theilla M, Cohen J, Singer P. Early administration of protein in critically ill patients: a retrospective cohort study. Nutrients. 2019;11(1):106.

9. Singer P, Anbar R, Cohen J, Shapiro H, Shalita-Chesner M, Lev S, et al. The tight calorie control study (TICACOS): a prospective, randomized, controlled pilot study of nutritional support in critically ill patients. Intensive care medicine. 2011;37(4):601-9.

10. Heidegger CP, Berger MM, Graf S, Zingg W, Darmon P, Costanza MC, et al. Optimisation of energy provision with supplemental parenteral nutrition in critically ill patients: a randomised controlled clinical trial. The Lancet. 2013;381(9864):385-93. 
11. Weijs PJ, Stapel SN, de Groot SD, Driessen RH, de Jong E, Girbes AR, et al. Optimal protein and energy nutrition decreases mortality in mechanically ventilated, critically ill patients: a prospective observational cohort study. Journal of parenteral and enteral nutrition. 2012;36(1):60-8.

12. Compher C, Chittams J, Sammarco T, Nicolo M, Heyland DK. Greater protein and energy intake may be associated with improved mortality in higher risk critically ill patients: a multicenter, multinational observational study. Critical care medicine. 2017;45(2):156-63.

13. Allingstrup MJ, Kondrup J, Wiis J, Claudius C, Pedersen UG, Hein-Rasmussen R, et al. Early goaldirected nutrition versus standard of care in adult intensive care patients: the single-centre, randomised, outcome assessor-blinded EAT-ICU trial. Intensive care medicine. 2017;43(11):1637-47.

14. Koekkoek WACK, van Setten CHC, Olthof LE, Kars JCNH, van Zanten ARH. Timing of PROTein INtake and clinical outcomes of adult critically ill patients on prolonged mechanical VENTilation: The PROTINVENT retrospective study. Clinical nutrition (Edinburgh, Scotland). 2019;38(2):883-90.

15. Hiesmayr M, Csomos A, Dams K, Elke G, Hartl W, Huet O, et al. Protocol for a prospective cohort study on the use of clinical nutrition and assessment of long-term clinical and functional outcomes in critically ill adult patients. Clinical Nutrition ESPEN. 2021;43:104-10.

16. Tipping CJ, Bailey MJ, Bellomo R, Berney S, Buhr H, Denehy L, et al. The ICU mobility scale has construct and predictive validity and is responsive. A multicenter observational study. Annals of the American Thoracic Society. 2016;13(6):887-93.

17. Peterson CM, Thomas DM, Blackburn GL, Heymsfield SB. Universal equation for estimating ideal body weight and body weight at any BMI. The American journal of clinical nutrition. 2016;103(5):1197-203.

18. Verreijen AM, Engberink MF, Houston DK, Brouwer IA, Cawthon PM, Newman AB, et al. Dietary protein intake is not associated with 5 -y change in mid-thigh muscle cross-sectional area by computed tomography in older adults: The Health, Aging, and Body Composition (Health ABC) Study. The American journal of clinical nutrition. 2019;109(3):535-43.

19. Brandi LS, Santini L, Bertolini R, Malacarne P, Casagli S, Baraglia AM. Energy expenditure and severity of injury and illness indices in multiple trauma patients. Critical care medicine. 1999;27(12):2684-9.

20. Choi EY, Park DA, Park J. Calorie intake of enteral nutrition and clinical outcomes in acutely critically ill patients: a meta-analysis of randomized controlled trials. Journal of Parenteral and Enteral Nutrition. 2015;39(3):291-300.

21. Tian F, Wang X, Gao X, Wan X, Wu C, Zhang L, et al. Effect of initial calorie intake via enteral nutrition in critical illness: a meta-analysis of randomised controlled trials. Critical Care. 2015;19(1):1-13.

22. Bender A, Groll A, Scheipl F. A generalized additive model approach to time-to-event analysis. Statistical Modelling. 2018;18(3-4):299-321.

23. Bender A, Scheipl F, Hartl W, Day AG, Küchenhoff H. Penalized estimation of complex, non-linear exposure-lag-response associations. Biostatistics. 2019;20(2):315-31.

24. Bender A SF, Kopper P. pammtools: Piece-Wise Exponential Additive Mixed Modeling Tools for Survival Analysis [Available from: https://cran.r-project.org/web/packages/pammtools/index.html. 
25. Kopper P. Flexible estimation of complex effects in the context of competing risks survival analysis: Ludwig Maximilian University; 2020. DOI: 10.5282/ubm/epub.72320 [updated 2020. Available from: https://epub.ub.uni-muenchen.de/72320/1/MA_Kopper.pdf.

26. Wood S. mgcv: Mixed GAM Computation Vehicle with Automatic Smoothness Estimation 1.8-34. 2021 [Available from: https://cran.r-project.org/web/packages/mgcv/index.html.

27. Hartl WH, Bender A, Scheipl F, Kuppinger D, Day AG, Küchenhoff H. Calorie intake and short-term survival of critically ill patients. Clinical Nutrition. 2019;38(2):660-7.

28. Hartl WH, Kopper P, Bender A, Scheipl F, Day AG, Elke G, et al. Protein intake and outcome of critically ill patients: analysis of a large international database using piece-wise exponential additive mixed models. Crit Care. 2022;26(1):7.

29. Ridley EJ, Parke RL, Davies AR, Bailey M, Hodgson C, Deane AM, et al. What Happens to Nutrition Intake in the Post-Intensive Care Unit Hospitalization Period? An Observational Cohort Study in Critically III Adults. Journal of Parenteral and Enteral Nutrition. 2019;43(1):88-95.

30. Ridley EJ, Peake SL, Jarvis M, Deane AM, Lange K, Davies AR, et al. Nutrition therapy in Australia and New Zealand intensive care units: an international comparison study. Journal of Parenteral and Enteral Nutrition. 2018;42(8):1349-57.

31. Preiser J-C, Arabi YM, Berger MM, Casaer M, McClave S, Montejo-González JC, et al. A guide to enteral nutrition in intensive care units: 10 expert tips for the daily practice. Critical Care. 2021;25(1):1-13.

32. Bendavid I, Singer P, Theilla M, Themessl-Huber M, Sulz I, Mouhieddine M, et al. NutritionDay ICU: a 7 year worldwide prevalence study of nutrition practice in intensive care. Clinical nutrition. 2017;36(4):1122-9.

33. Ingels C, Langouche L, Dubois J, Derese I, Vander Perre S, Wouters PJ, et al. C-reactive protein rise in response to macronutrient deficit early in critical illness: sign of inflammation or mediator of infection prevention and recovery. Intensive Care Medicine. 2021:1-11.

34. Arabi YM, Casaer MP, Chapman M, Heyland DK, Ichai C, Marik PE, et al. The intensive care medicine research agenda in nutrition and metabolism. Intensive care medicine. 2017;43(9):1239-56.

35. Rougier L, Preiser JC, Fadeur M, Verbrugge AM, Paquot N, Ledoux D, et al. Nutrition During Critical Care: An Audit on Actual Energy and Protein Intakes. Journal of Parenteral and Enteral Nutrition. 2021;45(5):951-60.

36. Elke G, Hartl WH, Kreymann KG, Adolph M, Felbinger TW, Graf T, et al. Clinical nutrition in critical care medicine-Guideline of the German Society for Nutritional Medicine (DGEM). Clinical nutrition ESPEN. 2019;33:220-75.

37. Davies ML, Chapple L-AS, Chapman MJ, Moran JL, Peake SL. Protein delivery and clinical outcomes in the critically ill: a systematic review and meta-analysis. Critical care and resuscitation. 2017;19(2):117-27.

38. Arabi Y, Al-Dorzi H, Mehta S, Tamim H, Haddad S, Jones G, et al. Association of protein intake with the outcomes of critically ill patients: a post hoc analysis of the PermiT trial. The American journal of 
clinical nutrition. 2018;108(5):988-96.

39. Fetterplace K, Deane AM, Tierney A, Beach LJ, Knight LD, Presneill J, et al. Targeted full energy and protein delivery in critically ill patients: a pilot randomized controlled trial (FEED trial). Journal of Parenteral and Enteral Nutrition. 2018;42(8):1252-62.

40. Ridley EJ, Davies AR, Parke R, Bailey M, McArthur C, Gillanders L, et al. Supplemental parenteral nutrition versus usual care in critically ill adults: a pilot randomized controlled study. Critical care. 2018;22:1-11.

41. Dresen E, Weißbrich C, Fimmers R, Putensen C, Stehle P. Medical high-protein nutrition therapy and loss of muscle mass in adult ICU patients: A randomized controlled trial. Clinical Nutrition. 2021;40(4):1562-70.

\section{Tables}

Table 1: Description of hypothetical medical nutrition therapies. 
Medical nutrition therapy

\section{Early}

low,

moderate, or

high calorie/protein intake

Late

low,

moderate, or

high calorie/protein intake

\section{Exclusively}

low,

moderate, or

high calorie/protein intake
Description

\section{feeding on days \#1 to \#4}

$<10 \mathrm{kcal} / \mathrm{kg}$ per day, or $<0.8 \mathrm{~g}$ protein $/ \mathrm{kg}$ per day

$10-20 \mathrm{kcal} / \mathrm{kg}$ per day, or $0.8-1.2 \mathrm{~g}$ protein/kg per day

$>20 \mathrm{kcal} / \mathrm{kg}$ per day, or $>1.2 \mathrm{~g}$ protein $/ \mathrm{kg}$ per day

\section{feeding on days \#5 to \#15}

$<10 \mathrm{kcal} / \mathrm{kg}$ per day, or $<0.8 \mathrm{~g}$ protein/kg per day,

$10-20 \mathrm{kcal} / \mathrm{kg}$ per day, or $0.8-1.2 \mathrm{~g}$ protein/kg per day

$>20 \mathrm{kcal} / \mathrm{kg}$ per day, or $>1.2 \mathrm{~g}$ protein/kg per day

\section{feeding on days \#1 to \#15}

$<10 \mathrm{kcal} / \mathrm{kg}$ per day, or $<0.8 \mathrm{~g}$ protein/kg per day

$10-20 \mathrm{kcal} / \mathrm{kg}$ per day, or $0.8-1.2 \mathrm{~g}$ protein/kg per day

$>20 \mathrm{kcal} / \mathrm{kg}$ per day, or $>1.2 \mathrm{~g}$ protein/kg per day

Number of days with a defined level of medical nutrition therapy starts with the day of ICU admission (day \#1).

Table 2. Demographic, nutrition, clinical and follow-up characteristics of the study population 
Characteristic $\left(\mathrm{n}=1172^{\mathrm{a}}\right)$

Age, years

Sex

Male

Female

BMl, $\mathrm{kg} / \mathrm{m}^{2}, \mathrm{n}=1168$

APACHE II score at ICU admission, $n=1132$

SOFA score at ICU admission, $\mathrm{n}=1042$

Number of comorbidities at ICU admission

Type of ICU admission

Non-surgical emergency

Surgical emergency

Surgical elective

Others

Main reason(s) for ICU admission ${ }^{b}$

Respiratory

Infection

Cardiac

Hepatic/Gl/digestive

Neurological

Renal

Trauma

Others

Sedation $^{c}$

Sum of days on sedation, $\mathrm{n}=885$

Vasopressors ${ }^{\mathrm{C}}$

Sum of days on vasopressors, $n=886$

Ventilatory support ${ }^{\mathrm{c}, \mathrm{d}}$
No. (\%) or Median [Q1;Q3]

$66.0[56.0 ; 74.0]$

$745(63.6)$

427 (36.4)

$26.8[24.0 ; 31.1]$

$18.5[13.0 ; 26.0]$

$7.0[4.0 ; 10.0]$

$3.0[1.0 ; 5.0]$

$573(48.9)$

$360(30.7)$

$220(18.8)$

$19(1.6)$

$546(46.6)$

$362(30.9)$

$343(29.3)$

279 (23.8)

$134(11.4)$

$126(10.8)$

116 (9.9)

74 (6.3)

885 (75.5)

$5.0[2.0 ; 10.0]$

886 (75.6)

$4.0[2.0 ; 8.0]$

988 (84.3) 
Sum of days on ventilatory support, $n=988$

Invasive mechanical ventilation between day 1 to 3 of ICU admission

Physiotherapyc

Sum of days on physiotherapy, $\mathrm{n}=1006$

Healthcare-associated infections after day 3 of ICU admission

Days in ICU until first infection, $\mathrm{n}=230$

Mobility status (IMS score)

before ICU admission, $\mathrm{n}=1168$

at day $15, n=1057$

at day $30, n=949$

at day $90, n=844$

ICU LOS, days, $\mathrm{n}=1158$

Hospital LOS, days, $n=1077$

ICU mortality, $n=1082$

Hospital mortality, $n=1082$

90-day mortality, $\mathrm{n}=1172$

Abbreviations: APACHE=acute physiology and chronic health evaluation, $\mathrm{BMI}=$ body mass index, $\mathrm{ICU}=$ intensive care unit, IMS=ICU mobility scale, IQR=interquartile range, LOS=length of stay, SOFA= sequential organ failure assessment

a Unless otherwise indicated
$7.0[4.0 ; 13.0]$

$813(69.4)$

$1006(85.8)$

$7.0[4.0 ; 11.0]$

$230(19.6)$

$6.0[4.0 ; 9.0]$

$10.0[8.0 ; 10.0]$

$10.0[8.0 ; 10.0]$

$5.0[1.0 ; 10.0]$

$9.0[3.0 ; 10.0]$

$10.0[9.0 ; 10.0]$

$10.0[7.0 ; 16.0]$

$23.0[15.0 ; 36.0]$

$168(15.5)$

$244(22.6)$

$276(23.5)$

\footnotetext{
${ }^{\mathrm{b}}$ Multiresponse variable

${ }^{c}$ On at least one day during the up to 15 observation days.

${ }^{d}$ Includes invasive, non-invasive ventilation and high flow nasal oxygen therapy
}

\section{Figures}

\section{Figure 1}

Daily calorie and protein intake, and distribution of nutrition resources 
Intake is presented as median, interquartile range, minimum and maximum values with outliers versus pre-defined targets (blue horizontal bars) based on the 2019 ESPEN Guideline on Clinical Nutrition in Critical Care1, and with proportion of nutrition resources used on a respective day.

ESPEN-defined daily calorie intake targets were $10 \mathrm{kcal} / \mathrm{kg}$ on D1, $15 \mathrm{kcal} / \mathrm{kg}$ on D2-D3, $20 \mathrm{kcal} / \mathrm{kg}$ on D4D6, $25 \mathrm{kcal} / \mathrm{kg}$ on D7-D15. ESPEN-defined daily protein intake targets were $0.6 \mathrm{~g} / \mathrm{kg}$ on D1, $0.9 \mathrm{~g} / \mathrm{kg}$ on D2-D3, $1.3 \mathrm{~g} / \mathrm{kg}$ on D4-D15. Non-nutritional calories included the use of glucose solutions, propofol, clevidipine, and citrate from renal replacement therapy. Patients without any nutrition on a respective day were counted with $0 \mathrm{kcal}$ or $0 \mathrm{~g}$ protein. The EN and/or PN categories also included patients who had received small amounts of calories/protein from oral nutrition/ONS.

Abbreviations: $\mathrm{EN}=$ enteral nutrition, $\mathrm{ON}=$ oral nutrition, $\mathrm{ONS}=$ oral nutritional supplements, $\mathrm{PN}=$ parenteral nutrition

\section{Figure 2}

Confounder-adjusted, time-varying association of a medical nutrition therapy providing fewer vs more calories with outcomes

Columns 1 and 4: Hypothetical medical nutrition therapy comparisons analyzing different levels of daily calorie intakes: low: $<10 \mathrm{kcal} / \mathrm{kg}$; moderate: 10-20 kcal/kg; high: $>20 \mathrm{kcal} / \mathrm{kg}$ (Table 1).

Column 2 and 3, and 5 and 6: Corresponding time-varying associations of different hypothetical medical nutrition therapies with the hazard of successful weaning from invasive mechanical ventilation (IMV), or 90-day mortality.

Grey areas indicate days with an identical calorie intake. Due to specifications of the model this intake could have been at any intake level.

Solid lines indicate hazard ratios (HR), hatched lines indicate corresponding 95\% confidence intervals (Cl). Reference medical nutrition therapy is the one which provides fewer calories (e.g., a HR (and 95\% $\mathrm{Cl}$ ) $<1$ would indicate a longer survival time but also a longer time until extubation associated with the medical nutrition therapy providing more calories).

Please note that HRs (and corresponding $95 \% \mathrm{Cls}$ ) must be 1 for the first time 2 days for IMV and 4 days for survival due to the specification of the lag time, and also for time intervals, in which calorie intake was identical within the relevant time window that affects the hazard. From the 90-day survival analysis, the HRs for the first 30 days are displayed due to estimation stability as the majority of deaths occurred until this day. 


\section{Figure 3}

Confounder-adjusted, time-varying association of a medical nutrition therapy providing fewer vs more protein with outcomes

Columns 1 and 4: Hypothetical medical nutrition therapy comparisons analyzing different levels of daily protein intake: low: $<0.8 \mathrm{~g} / \mathrm{kg}$; moderate: 0.8-1.2 g/ $\mathrm{kg}$; high: $>1.2 \mathrm{~g} / \mathrm{kg}$ (Table 1).

Column 2 and 3, and 5 and 6: Corresponding time-varying associations of different hypothetical medical nutrition therapies with the hazard of successful weaning from invasive mechanical ventilation (IMV), or 90-day mortality.

Grey areas indicate days with an identical protein intake. Due to specifications of the model this intake could have been at any intake level.

Solid lines indicate hazard ratios (HR), hatched lines indicate corresponding 95\% confidence intervals (Cl). Reference medical nutrition therapy is the one which provides fewer protein (e.g., a HR (and 95\% $\mathrm{Cl}$ ) < 1 would indicate a longer survival time but also a longer time until extubation associated with the medical nutrition therapy providing more protein).

Please note that HRs (and corresponding 95\% Cls) must be 1 for the first time 2 days for IMV and 4 days for survival due to the specification of the lag time, and also for time intervals, in which protein intake was identical within the relevant time window that affects the hazard. From the 90-day survival analysis, the HRs for the first 30 days are displayed due to estimation stability as the majority of deaths occurred until this day.

\section{Supplementary Files}

This is a list of supplementary files associated with this preprint. Click to download.

- EuroPNAdditionalfile1.docx

- EuroPNGraphicalabstract.jpg 